\title{
Sleep in the Greek Mythology
}

\author{
Sooyeoun You \\ Department of Neurology, Keimyung University School of Medicine, Daegu, Korea
}

그리스 신화 속 수면

유 수 연

계명대학교 의과대학 신경과학교실

Received March 24, 2019

Revised May 10, 2019

Accepted May 14, 2019

Address for correspondence

Sooyeoun You, MD

Department of Neurology,

Keimyung University

School of Medicine,

1035 Dalgubeol-daero,

Dalseo-gu, Daegu 42601, Korea

Tel: $+82-53-258-7838$

Fax: +82-53-258-4380

E-mail: omoi81@hanmail.net
Objectives: There was also an observation about the "sleep" in the Greek era, which is called the primordial current of modern medicine, which is interpreted as a phenomenon organized by God and appears in various forms in Greek mythology. Methods: We used the words 'Greek mythology', 'Sleep,' 'God of Sleep,' 'Greece, and 'myth' in English and Korean on Google site for information on sleep in Greek mythology. Results: In Greek mythology, stories appeared about the sleeping god Hypnos, his wife Pasithea, and the dream gods Oneiroi, to explain the mystery of sleep. The various ideas of ancient Greeks' sleep are reflected in legends about Ceyx and Alcyone, Psyche, Endymion, Ariadne, Argos, and Polyphemus. Conclusions: The images of sleep in Greek mythology that have continued for decades include observations and experiences of mankind. This can be interpreted from a medical point of view as the important significance of sleep on humans.

J Sleep Med 2019;16(1):21-25

\section{서 론}

수면은 감각능력이 억제되고, 자발적인 움직임이 감소되 며, 주변 환경과 자극에 대한 반응이 떨어지는 상태가 자연 적으로, 그리고 주기적으로 반복되는 상태를 말한다. ${ }^{1}$ 현대 의학에서 수면은 단순한 휴식이 아니라 건강을 위해 반드시 필요한 과정으로 받아들여지고 있다. 수면이 부족하거나 수 면의 질이 나빠질 경우에 일상생활에 큰 장애가 발생하고, 각종 질환의 위험성이 높아지는 것은 잘 알려진 사실이다.

우리는 하루의 $1 / 4$ 에서 $1 / 3$ 을 잠으로 보내는데, 인류의 역 사 초기부터 수면에 대한 인식이 있어왔다. 현대의학의 원류 라고 불리우는 그리스 시대에도 '잠'이라는 현상에 대한 관 찰이 있었으며, 이것은 신이 주관하는 현상으로 해석되어 그 리스 신화 속에서 다양한 모습으로 등장한다. 이 원저에서 우리는 그리스 신화 속에 나타난 다양한 수면의 모습에 대

This is an Open Access article distributed under the terms of the Creative Commons Attribution Non-Commercial License (https://creativecommons.org/licenses/by-nc/4.0) which permits unrestricted non-commercial use, distribution, and reproduction in any medium, provided the original work is properly cited.
해 알아보면서, 현대의학에서 사용하는 수면 관련 용어의 어 원을 알아보고 수천 년 전과 현재의 수면에 대한 인식을 비 교하여 서술하고자 한다.

\section{방 법}

그리스 신화 속 수면에 대한 정보를 얻기 위하여 Google 에서 영문으로 'Greek mythology', 'Sleep', 'God of sleep', 'Greece', 그리고 'myth'라는 키워드를 자료 검색에 사용하 였다. 한글로도 '그리스 신화', ‘수면', ‘수면의 신', 그리고 '신 화라는 키워드를 사용하여 관련 문헌에 대하여 검색하였다. 이 검색 결과를 통해 나온 신화 속 신, 인물, 그리고 일화에 관련된 정보를 추가로 검색하여 좀 더 자세한 내용을 얻을 수 있었다. 이를 통해 그리스 신화 속 수면에 관련된 상세한 정보들을 수집하였고, 각각의 내용들을 정리하였다. 


\section{결 과}

\section{수면에 관여하는 신들}

그리스 신화 속의 신들은 모두 인간의 모습을 취하고 있 으며, 그 성격이나 생활도 인간과 흡사하다. 그리하여 보통 신들에게도 부부나 자식과 같은 일반적인 가족 관계가 설정 되어 있으며, 비슷한 성향의 신들끼리 가족으로 엮기도 하 며, 혹은 주요 신의 가족들은 주요 신들의 권능과 관련된 역 할을 나눠 갖고 있다는 방식으로 신화를 풀어나간다.

\section{히프노스(Hypnos, 그리스어: "Y $\pi v o \varsigma)$}

히프노스는 현대에 사용되는 수면제(hypnotics)와 최면 (hypnosis)이라는 영어 단어의 어원이 되는 신으로, 그리스 신화 속에서 수면을 담당하는 잠의 신이다. ${ }^{2}$ 밤의 여신인 닉

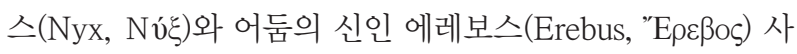
이에서 태어났다고 하며, 죽음의 신(Thanatos, $\Theta \alpha ́ v \alpha \tau O \zeta)$ 과 쌍둥이 형제로 미술 작품 속에서도 그 모습을 찾아볼 수 있 다(Fig. 1). ${ }^{3,4}$ 신화 속에서 히프노스가 사는 곳은 명계 근처이 다. 죽은 사람들의 땅인 명계에는 다섯 개의 강이 흐르고 있 는데, 그중에 '망각의 강'이라고 불리우는 레테(Lethe, $\Lambda \eta \emptyset \eta)$ 옆에 히프노스가 사는 동굴이 있다. 망각의 강 옆에 잠의 신 의 거처가 있다는 것도 수면에 대한 비유라고 볼 수 있는데, 잠을 자고 나면 그 이전의 일이나 수면 중의 일들에 대해 잊 게 되는 것을 보며 만든 이야기일 수 있겠다. 이 수면의 신의 거처 주위는 양귀비 씨앗(poppy seed)들로 가득 차 있으며, 항상 잠들어 있는 히프노스를 위해 거의 빛이 들지 않고 매 우 조용한 환경이 조성되어 있다. ${ }^{4}$ 다른 신들도 히프노스의 거처를 방문하면 그의 권능 탓에 잠이 쏟아진다고 한다. 헤 라 여신의 전령인 무지개의 여신 이리스(Iris, ${ }^{2} \mathrm{I} \rho 1 \varsigma$ )가 히프

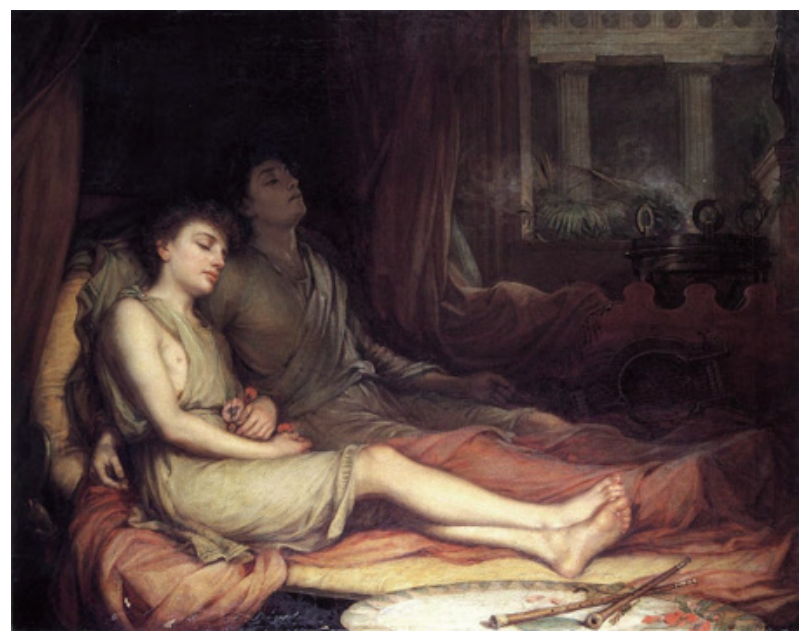

Figure 1. Hypnos and Thanatos, Sleep and his half-brother Death, John William Waterhouse (1874).
노스에게 부탁할 일이 있어 방문했을 때도 거처의 입구에서 부터 잠이 쏟아져, 헤라 여신의 전언만 전달하고 빨리 떠났 다는 이야기가 나온다. 히프노스는 거처에서 잠을 자며, 인 간들에게 꿈으로 여러 가지 메시지를 전달할 필요가 있을 때는 그의 자손들인 꿈의 신들에게 일을 맡긴다. 이러한 히 프노스의 신화적 기원은, 사람들이 보통 어두운 밤 시간에 수면 상태에 빠지며, 잠든 상태의 신체가 평소보다 체온이 낮고 움직임도 없으며, 호흡도 느려지는 것을 보며 죽음에 가깝다고 생각한 것이 반영된 것으로 사료된다. 히프노스의 로마식 이름은 '솜누스(Somnus)'로, 현대에 사용되는 수많 은 수면 관련 단어에 나타나 있다(예: insomnia, parasomnia, somnolence, polysomnography, etc.). ${ }^{5}$

\section{히프노스의 가족들}

히프노스의 가족들 역시 모두 잠과 관련된 권능을 지니고 있다. 히프노스의 부인은 '카리테스(Carites)'라고 불리는 우 미(優美, grace)의 세 여신 중 한 명인 '파시테아(Pasithea, П $\alpha \sigma(\theta \varepsilon))^{\prime}$ 이다. 파시테아는 명상을 담당하고 있으며, 이는 수 면 전에 조용한 환경에서 명상을 취하기 좋다는 은유일 수 도 있다. 외국의 한 연구에서는 수면무호흡증 모니터링 및 치료 시스템의 약자를 PASITHEA라고 붙인 바 있다. ${ }^{6}$ 히프 노스와 파시테아는 천 명에 이르는 자식들을 낳았다고 하며, 그들은 '오네이로이(Oneiroi, 'Oveíp $\omega v)$ '라고 불리었다. 이들 은 모두 꿈의 신으로 꿈속에 나타나는 여러가지 현상들을 의인화한 신들이다. 천 명에 이르는 오네이로이 중에서 가장

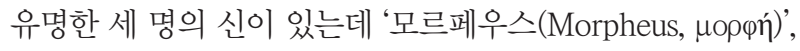
'포베토르(Phobetor, $\Phi$ o $\eta \tau \omega \rho)$ )', '판타소스(Phantasos, $\Phi \alpha v \tau$ $\alpha \sigma o s)^{\prime}$ '이다. 이 중에서 모르페우스는 주로 꿈에서 사람의 모 습으로 나타나며, 어떤 사람의 모습으로든 변신할 수 있는 능력이 있어서 꿈속에서 여러 가지 메시지를 전하는 전령의 역할을 맡았다. ${ }^{7}$ 변형을 뜻하는 'morphosis'라는 영어 단어의 기원과 관련되어 있으며, 유명 영화인 매트릭스(Matrix)의 주요 인물 중 하나인 '모피어스'는 모르페우스의 영어식 발 음이다. 포베토르는 이켈로스(Icelos)라고도 하며, 짐승이나 괴물의 형상을 취할 수 있어 악몽의 신으로도 불리며 “놀라 게 만드는 자(frightener)"이다. 포베토르는 공포를 뜻하는 단어인 'phobia'의 어원과 연관되어 있다. 끝으로 판타소스 는 바위나 나무 등의 온갖 사물로 변신할 수 있어서 '환상의 신(God of fantasy)'이라는 이명을 가지고 있다. ${ }^{7}$

\section{신화 속에 나타나는 수면}

그리스 신화 속에서 잠이나 꿈에 대한 이야기는 여러 번 등장하며, 이야기마다 잠의 의미도 다양하게 나타난다. 여러 
이야기 중에서 가장 널리 알려진 것들을 중심으로 하여, 크 게 세 가지의 분류에 따라 잠에 관련된 이야기들을 정리해 보고자 한다.

\section{신의 메시지로서의 수면과 꿈 이야기}

수면 중에 나타나는 꿈은 영적인 존재가 전달하는 메시지 가 담겼다고 여기는 경우가 있다. 그리스 신화에서도 신의 지시를 전달하는 매개로서의 꿈 이야기가 나오는데, 그중에 서 가장 자세히 묘사되는 것으로 '케익스(Ceyx, $\mathrm{K} \eta \dot{\eta} \ddot{\xi})$ '와

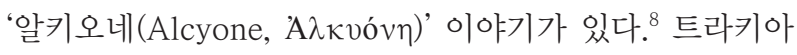
(Trachis, T paxis)의 왕이었던 케익스는 선정을 베풀던 훌륭 한 군주로, 왕비인 알키오네와 금슬도 좋은 부부 사이로 행 복한 삶을 누리고 있었다. 그러던 어느 날부터 나라 안에 여 러 가지 재앙이 일어나, 그 원인을 알기 위해[전승에 따라서

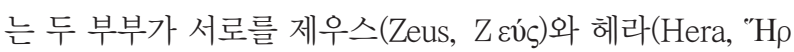
$\bar{\alpha})$ 로 불러서 신의 노여움을 샀다는 설도 있다] 아폴론(Apol-

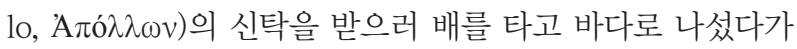
태풍에 침몰하여 익사하게 된다. 그러나 남편의 죽음을 알지 못했던 알키오네 왕비는 매일같이 헤라 여신에게 남편의 무 사 귀환을 기원하였고, 죽은 자를 위한 끝없는 기도를 견디 지 못한 헤라 여신이 꿈을 통해 남편의 죽음을 알려주고자 한다. 그리하여 헤라는 히프노스에게 부탁하여 케익스의 죽 음을 알키오네에게 알려주라고 하였고, 히프노스는 모르페 우스를 보내어 그 일을 진행하도록 한다. 모르페우스는 변신 에 능한 신답게, 물에 빠져 죽은 케익스의 모습으로 알키오 네의 꿈속에 나타나 자신은 익사하였으며 자신의 시체가 곧 테살리아(Thessaly, $\Theta \varepsilon \sigma \sigma \alpha \lambda i ́ \alpha)$ 의 앞바다로 실려올 테니 장 례를 지내달라고 부탁하였다(Fig. 2A). 결국 남편의 시체를 발견한 알키오네는 바다에 몸을 던져 자살하였고(Fig. 2B),
두 부부는 모두 물총새(halcyon)로 변했다고 한다.

\section{아름다움의 비밀}

'신의 잠'은 아름다움을 회복하고 유지하는 비법인 것처럼 표현된 이야기들도 있다. '에로스(Eros, ”E $\left.{ }^{\prime} \omega \varsigma\right)$ '와 '프시케 (Psyche, $\Psi v x \eta \dot{n})^{\prime}$ 의 사랑 이야기에서, 에로스의 어머니인 아 프로디테는 에로스가 사랑하는 프시케에게 여러 가지 시련 을 내리는데, 그중의 하나가 명계의 여주인인 '페르세포네

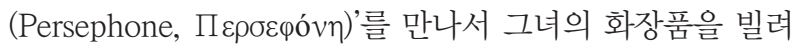
오라는 것이었다. 에로스의 도움으로 명계까지 무사히 가서 화장품이 담긴 황금 상자를 받아온 프시케는 호기심을 못 이기고 상자를 열어보는데, 그 안에는 '신의 잠'이 들어있었 고, 인간의 몸으로 신의 잠을 취하자 죽은 것처럼 깊은 잠에 빠지게 된다. 결국은 에로스의 도움으로 죽음과도 같은 깊은 잠에서 깨어나게 되는데, 이러한 일화는 깊은 잠이 아름다움 의 비법이라는 비유일 수도 있고, 신의 영역을 함부로 들여 다보면 큰 재앙을 얻을 수도 있다는 교훈을 주는 것으로도 생각할 수 있다.

아름다움과 잠에 관련된 또 하나의 이야기로 '엔디미온

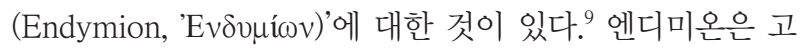

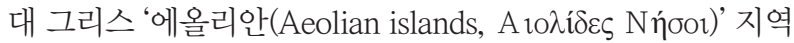
의 양치기로 그 미모가 유명했는데, 어느 날 그를 보고 사랑 에 빠진 달의 여신 '셀레네(Selene, $\Sigma \varepsilon \lambda \eta \eta \eta \eta)$ '가 '그의 젊음과 아름다움이 영원한 채로 내 곁을 떠나지 않기를' 바라게 되 었고, 그녀의 부탁을 들은 제우스가 그를 영원한 잠에 빠지 게 만들었다고 한다(Fig. 3). 그리고 셀레네는 잠든 엔디미온 과의 사이에서 50 명의 딸을 낳았는데, 이는 그리스 달력에서 의 50 개의 달(Lunar months)을 의미하며, 이 기간이 총 4년 이 된다. 학자들에 따라서는 이 4년의 기간을 올림픽이 열리
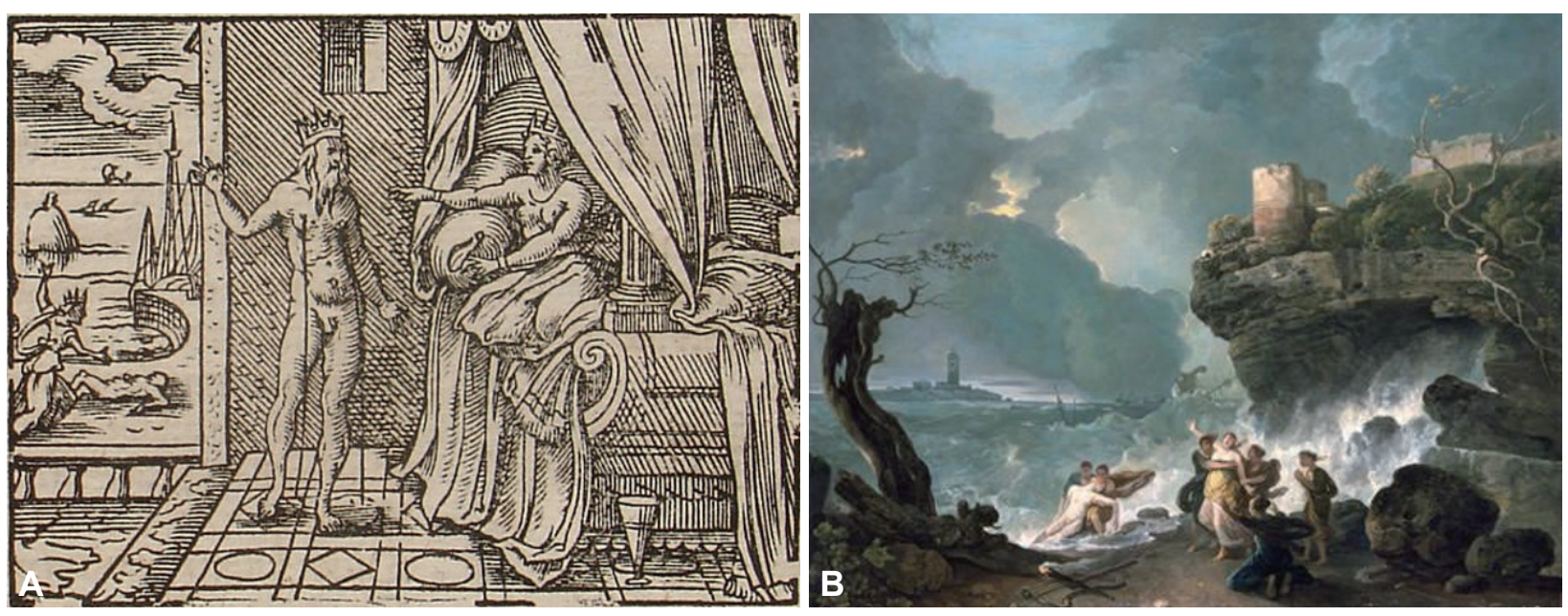

Figure 2. (A) Alcyone \& Ceyx/Morpheus, Virgil Solis (650-749). (B) Ceyx and Alcyone, Richard Wilson (1768). 


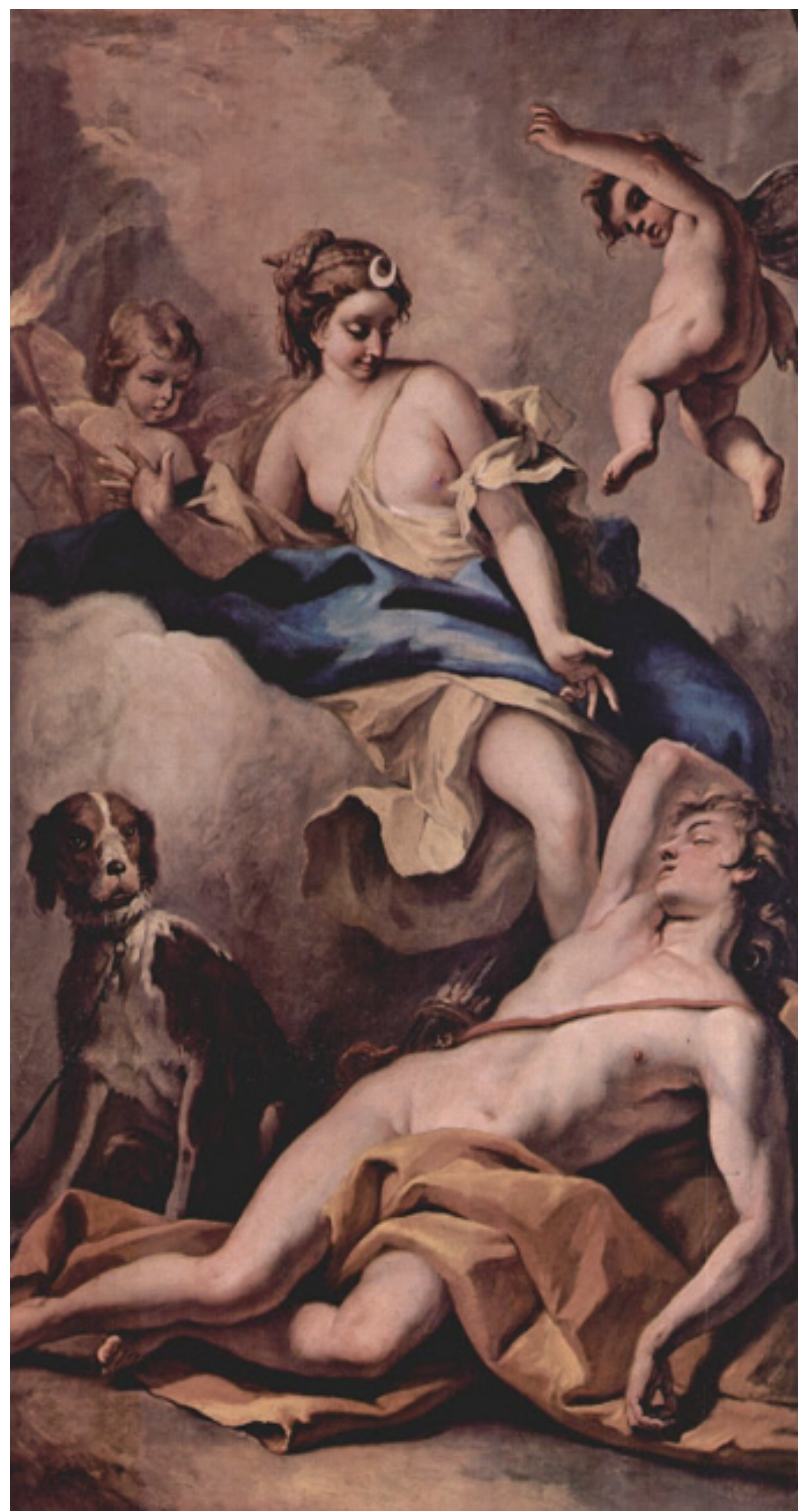

Figure 3. Selene and Endymion, Sebastiano Ricci (1713).

는 주기로 보기도 한다. ${ }^{10}$ 이 이야기는 신이 내린 영원한 잠이 인간의 아름다움을 영구히 보존하는 역할을 하는 모습을 보 여준다. 한편으로는 신의 사랑 혹은 욕망 때문에 한 인간의 삶이 '잠에 빠진 채’로만 유지되는 비극으로도 볼 수 있겠다.

\section{수면 중에 일어나는 상실}

수면 중의 인간은 무방비한 상태가 되기 때문에, 수면 중 에 많은 것을 잃게 되는 그리스 신화 속 이야기는 잠에 빠진 인간(혹은 인간과 비슷한 존재들)의 무력함을 나타내기도 한다.

'아리아드네(Ariadne, Aplá $\delta v \eta)$ '는 테세우스(Theseus, $\Theta \eta$

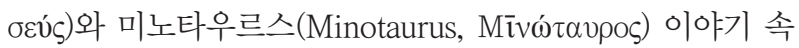

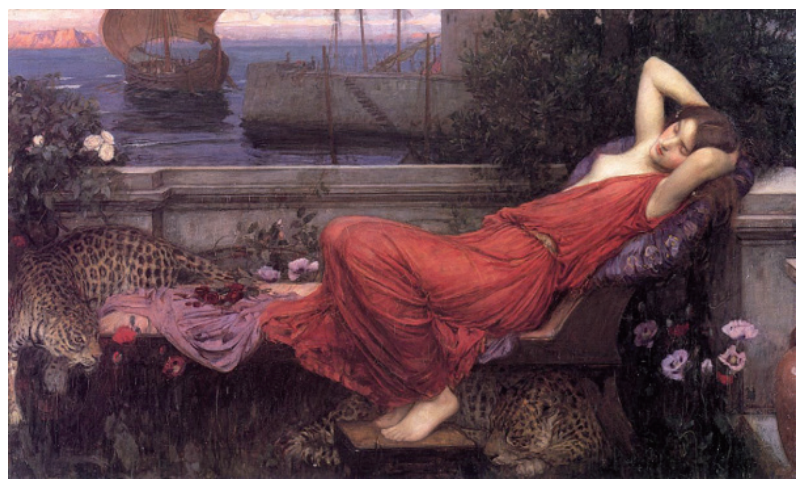

Figure 4. Ariadne, John William Waterhouse (1898).

의 여주인공으로, 그녀가 사랑하게 된 아테네의 왕자 테세우 스에게 실타래를 주어 그가 미궁을 빠져나오는 데 도움을 주었다. 그리고 테세우스와 함께 아테네로 떠나 그의 왕비가 되기로 했는데, 항해 도중 들린 낙소스(Naxos, $\mathrm{Na \xi}$ oo) 섬에 서 그녀가 잠든 사이에, 그녀를 제외한 모든 이가 출항하여 혼자 남겨지게 되었다(Fig. 4). 결국 사랑하는 사람에게 버림 받은 것이 되었고, 이는 잠에 의한 망각과 상실을 보여주는 이야기라고 생각할 수 있다.

잠으로 인해 목숨과 신체 일부를 잃게 되는 이야기들도 있다. '아르고스(Argos, 'Apros)'라는 백 개의 눈을 가진 괴물 은 헤라 여신의 명령으로, 제우스의 연인인 이오(Io, 'I 변신한 암소를 감시하게 되었다. 그런데 이 아르고스는 연인 을 구해주고 싶었던 제우스가 파견한 헤르메스(Hermes, ${ }^{\mathrm{E}} \mathrm{\rho}$ $\mu \tilde{\eta} \varsigma)$ 의 리라(lyre, $\lambda \dot{v} \rho \alpha)$ 소리에 잠들었고, 그 틈에 목이 베이 고 그의 눈은 모두 뽑혀 헤라 여신의 새인 공작의 깃털에 박 히게 되었다. 이 이야기는 적절한 음악이 수면 유도에 도움 이 된다는 현대의학의 연구 결과와 함께 볼 때 더욱 흥미롭 다. ${ }^{11,12}$ 또 다른 상실의 이야기로는 '폴리페모스(Polyphemus,

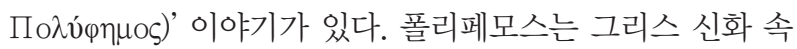

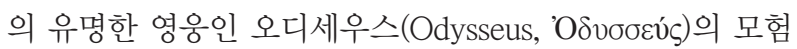
기 속에 나오는 외눈박이 괴물인데, 자신의 섬에 상륙한 오 디세우스 일행을 잡아 가두고 매일 한두 명씩 잡아먹었다. 이에 오디세우스는 괴물로부터 탈출하기 위한 지혜를 발휘 하여, 폴리페모스에게 포도주를 잔뜩 먹여 잠들게 하였다. 그리고 그 사이에 그의 눈을 도려내고 양 떼 사이에 숨어 탈 출하게 된다. 이 이야기 속에서 술에 취해 잠드는 폴리페모 스의 모습은 현대의학에서 밝혀진 술에 의한 수면의 변화와 연관하여 생각해보면 매우 잘 설명된 것이라고 볼 수 있다. 술을 마실 경우, 정상 수면보다 수면 시작 지연 시간(sleep latency)이 감소하고, 전반기 첫 수면이 강화된다고 알려져 있는데 ${ }^{13}$ 폴리페모스가 잠에 빠져 눈을 도려낼 때까지 깨어 나지 못한 것이 술에 의해 유도된 수면의 묘사이다. 이와 같 
은 이야기들은 수면 중 일어나는 외부 자극에의 반응성 저 하를 보여주며, 이로 인해 수면 중에 위험을 당할 수 있다는 것을 보여준다.

\section{고 찰}

그리스 신화 속 수면의 신들과, 수면에 관련된 신화들을 살펴보았다. 고대의 사람들도 수면의 특징에 대해 깊은 고찰 을 하였으며, 수면의 다양한 현상에 대해서 비교적 자세하게 파악하여 각각의 증상과 현상에 대응하는 이야기를 만들어 낸 것으로 보이며, 수면 상태에서 보이는 외부 환경에 대한 반응 저하와 꿈의 존재, 기억과 회복, 그리고 아름다움(항상 성)에 이르기까지 수면의 개괄적 내용을 포함하고 있다. 현 대의학에서 사용하는 다양한 용어들은 이러한 신화에서 만 들어진 경우가 많으며, 그리스 신화의 전능한 신들마저도 수 면이 필요하고 또한 쉽게 이겨낼 수 없는 강력한 무언가로 그려졌다. 이것은 의학적 관점에서 수면이 인간에게 미치는 중요한 의의로 해석할 수 있다.

수십 세기를 이어온 그리스 신화에서 보여주는 수면의 모 습은 인류의 관찰과 경험이며, 인간의 믿음과 바람이 투영된 것이다. 동시에, 그 믿음과 바람의 진위를 과학적으로 검증 해야 하는 것이 현대의학의 사명이라고 생각한다. 본고의 내 용으로써 의사와 간호사 등의 의료인들뿐만 아니라 비의료 인도 수면 의학에 접근하기 쉬워지고, 또한 수면 의학의 저 변이 확대되는 것에 작은 도움이 되었으면 하는 바이다.

\section{Conflicts of Interest}

The author has no potential conflicts of interest to disclose.

\section{ORCID iD}

Sooyeoun You

https://orcid.org/0000-0003-4753-4491

\section{REFERENCES}

1. Korean Neurological Association. Textbook of Neurology. 3rd ed. Seoul: PanMun Education, 2017;515.

2. Mantinband JH. Concise dictionary of Greek literature. New York: Philosophical Library, 1962.

3. Vollmer W. Wörterbuch der Mythologie aller Völker. Reprint-VerlagLeipzig, 2003;263.

4. Littleton CS. Gods, goddesses, and mythology, vol. 4. New York: Marshall Cavendish, 2005;474-476.

5. Define "insomnia." Dictionary.com [cited 2014 Jan 27]. URL:https:// www.dictionary.com/browse/insomnia?s=t. Access 2019 April 23.

6. Hernández AI, Guerrero G, Feuersteinc D, et al. PASITHEA: an integrated monitoring and therapeutic system for sleep apnea syndromes based on adaptive kinesthetic stimulation. IRBM 2016;37:81-89.

7. Miller FJ (Trans.). Goold GP (Revised). Ovid. Metamorphoses, Volume II: Books 9-15. Cambridge: Harvard University Press, 1916.

8. Hesiod HH (Trans. Evelyn-White HG). Epic cycle, Homerica. London: William Heinemann, 1914;57.

9. Apollodorus. Apollodorus, The library, with an English translation by Sir James George Frazer, in 2 volumes. Cambridge: Harvard University Press, 1921.

10. Davidson J. Time and Greek religion. In: Ogden D. A companion to Greek religion. West Sussex: John Wiley \& Sons, 2010;204-218.

11. Trahan T, Durrant SJ, Müllensiefen D, Williamson VJ. The music that helps people sleep and the reasons they believe it works: a mixed methods analysis of online survey reports. PLoS One 2018;13:e0206531.

12. Jespersen KV, Otto M, Kringelbach M, Van Someren E, Vuust P. A randomized controlled trial of bedtime music for insomnia disorder. $J$ Sleep Res 2019:e12817.

13. Ebrahim IO, Shapiro CM, Williams AJ, Fenwick PB. Alcohol and sleep I: effects on normal sleep. Alcohol Clin Exp Res 2013;37:539-549. 